\title{
Erratum to: A case of perforated multiple gastric duplication cysts with five-layered appearance on ultrasonography
}

\author{
Nagaaki Marugami $\cdot$ Toshiko Hirai $\cdot$ Namiko Yamashita $\cdot$ Misuzu Yoshida \\ Hajime Ohishi · Banryoku Higuchi · Hiromichi Kanehiro $\cdot$ Yoshiyuki Nakajima
}

Published online: 26 October 2010

(C) The Japan Society of Ultrasonics in Medicine 2010

Erratum to: J Med Ultrasonics

DOI 10.1007/s10396-010-0282-7

There is an error in the last author's name. It should be Nakajima, not Nagajima.

The online version of the original article can be found under doi:10.1007/s10396-010-0282-7.

N. Marugami $(\bowtie) \cdot$ T. Hirai $\cdot$ N. Yamashita $\cdot$ M. Yoshida

H. Ohishi

Department of Endoscopy and Ultrasound, Nara Medical

University, Shijyo-cho 840, Kashihara, Nara 634-8522, Japan

e-mail: marugami@naramed-u.ac.jp

B. Higuchi

Department of Pediatrics, Nara Medical University,

Shijyo-cho 840, Kashihara, Nara 634-8522, Japan

H. Kanehiro · Y. Nakajima

Department of Surgery, Nara Medical University,

Shijyo-cho 840, Kashihara, Nara 634-8522, Japan 